far more difficult than for myocardial infarction; 20 years of trials have yet to provide an effective drug treatment for stroke. We will probably have to wait until the next century before treatments other than antithrombotic and anticoagulant treatment (for example, neuroprotection) have been tried in sufficient numbers of patients to assess their efficacy and safety adequately. Sadly, little regard has being given to developing treatments for primary intracerebral haemorrhage, although newer trials of neuroprotective agents (including the planned international stroke trial 2) are starting to include patients with this condition.

To accelerate the development of short term treatments for stroke six actions are necessary. Firstly, hospitals capable of participating in multicentre trials should join them to speed recruitment. Secondly, hospitals will need to open acute stroke units to facilitate such trials ${ }^{12}{ }^{13}$ (much as coronary care units made treatment of myocardial infarction trials possible). Thirdly, most ongoing trials require the involvement of patients within three to 12 hours of the onset of stroke. Patients, general practitioners, and hospital staff need to appreciate that early presentation to hospital will increase the population of patients eligible for, and hence who may benefit from, such trials; the National Institutes of Health's trial of tissue plasminogen activator managed to enrol 300 patients within 90 minutes of the onset of stroke so it is possible to greatly reduce the time that elapses before the initiation of treatment. Fourthly, some trials of drugs that alter haemostasis (especially thrombolytics, anticoagulants, and antithrombotics) require prior computed tomography to exclude primary haemorrhage; the routine availability of 24 hour tomography is now required in all acute hospitals.
Fifthly, short term drug treatments for primary intracerebral haemorrhage need to be developed. Lastly, systematic reviews spanning the whole range of the management of stroke are required to help define future lines of research.

PHILIP M W BATH

Wolfson senior lecturer in stroke medicine

Department of Medicine,

King's College School of Medicine and Dentistry,

London SE5 9PJ

1 Bonita R. Epidemiology of stroke. Lancet 1992;339:342-4.

2 Pulsinelli W. Pathophysiology of acute ischaemic stroke. Lancet 1992;339:533-6.

3 Hommel M, Boissel JP, Cornu C, Boutitie F, Lees KR, Beesson G, et al. Termination of trial of streptokinase in severe acute ischaemic stroke. Lancet 1995;345:57.

4 Donnan GA, Davis SM, Chambers BR, Gates PC, Hankey GJ, McNeil JJ, et al. Trials of streptokinase in severe acute ischaemic stroke. Lancet 1995;345:578-9.

5 Hacke W, Kaste M, Fieschi C, for ECASS Study Group. The efficacy of IV-rtPA in acute ischemic stroke: first results of the ECASS trial. Stroke 1995;26:167.

6 Counsell CE, Fraser H, Sandercock PAG. Archie Cochrane's challenge: can periodically updated reviews of all randomised controlled trials relevant to neurology and neurosurgery be produced? f Neurol Neurosurg Psychiatry 1994;57:529-33.

7 Wardlaw J, Yamaguchi T, del Zoppo G, Hacke W. Thrombolysis in acute ischaemic stroke. In Warlow C, Van Gijn J, Sandercock P, eds. Stroke module. Cochrane database of systematic reviews. London: BMJ Publishing, 1995. [Updated 9 March 1995.]

8 Counsell C, Sandercock P. The efficacy and safety of anticoagulant therapy in patients with acute presumed ischaemic stroke: a systematic review of the randomized trials comparing anticoagulants with control. In: Warlow C, Van Gijn J, Sandercock P, eds. Stroke module Cochrane database of systematic reviews. London: BMJ Publishing, 1995. [Updated 9 March 1995.]

9 Counsell C, Sandercock P. The efficacy and safety of antiplatelet therapy in acute presumed ischaemic stroke: a systematic review of the randomized trials comparing immediate antiplatelet therapy with control. In: Warlow C, Van Gijn J, Sandercock P, eds. Stroke module. Cochrane therapy with control. In: Warlow C, Van Gijn J, Sandercock P, eds. Stroke module.

10 Bath P, Bath F. A systematic review of prostacyclin and analogues in acute ischaemic stroke. In Warlow C, Van Gijn J, Sandercock P. eds. Stroke module. Cochrane database of systematic reviews. London: BMJ Publishing, 1995. [Updated 9 March 1995.]

1 Rogvi-Hansen B, Boysen G.l.v. glycerol treatment in acute ischaemic stroke. In: Warlow C, Van Gijn J, Sandercock P, eds. Stroke module. Cochrane database of systematic reviews. London: BM] Publishing, 1995. [Updated 9 March 1995.]

12 Morris AD, Grosset DG, Squire IB, Lees KR, Bone I, Reid JL. The experiences of an acute stroke unit-implications for multicentre acute stroke trials. $\mathcal{F}$ Neurol Neurosurg Psychiatry 1993;56: 352-5.

13 Bath PMW, Butterworth RJ, Soo J, Kerr J. The King's College Hospital Acute Stroke Unit. $f R$ Coll Physicians Lond (in press).

\title{
Workplace health in primary care premises
}

\section{Has been neglected}

One of the strategies of the Health of the Nation is to improve health in the workplace, especially in NHS workplaces. ${ }^{1}$ Health care is labour intensive, so better health of staff should lead to a more effective and economical service as well as directly benefiting employees. Staff sickness in the NHS is not accurately quantified but may cost many millions of pounds annually, ${ }^{2}$ much of it being due to avoidable causes such as back injury. As the NHS is founded on primary care one might expect the health of primary care staff, and of their workplaces, to have received particular attention. In fact, it remains underdeveloped and under researched.

This neglect reflects several biases. Firstly, initiatives within the health service have so far concentrated on hospitals, where there is economy of scale and a tradition of managerial control. Secondly, practices interested in ensuring a healthy workplace may not have the greatest need: poorly organised and overworked practices probably have more hazardous premises and their staff probably have worse health. Thirdly, for doctors and dentists one can obtain statistics such as deaths due to suicide or cirrhosis and point to responses such as the sick doctors scheme; but these can seldom be found for other grades of staff. These biases imply a law of inverse care for workplace health in primary care.

The neglect also reflects a curious culture in the workplace. Practices are independent, and their staff are not protected by NHS terms and conditions or by benefits such as NHS superannuation. They have no personnel departments to reconcile employers' and staff interests. They may choose to ignore guidance such as that on no smoking areas ${ }^{3}$ or on occupational health. ${ }^{4}$ General practitioners are knowledgeable about workplace health because so many consultations raise questions of fitness for work; indeed, many general practitioners have qualifications in occupational health. Yet they face a triple conflict of interest if they act as employer, occupational health medical officer, and family doctor to their own staff. Practice staff work alongside attached community staff, whose working conditions are therefore partly beyond the control of the employing trust, yet who do enjoy NHS benefits. These will include occupational health services, perhaps obtained by the community trust from a nearby hospital, which buys sessions from a local general practitioner. ...

The "health at work in the NHS" campaign is therefore welcome and timely, but what is in it for primary care? The campaign encourages practical measures such as extending no smoking areas, policies on use and misuse of alcohol, safe lifting and handling, and managing stress. Such measures are not costly, and one might expect that many primary care premises could benefit. Or could they? There are few hard data to bear out this expectation or to ensure that interventions are accurately targeted and sensitive to primary care's needs. The campaign therefore risks missing its mark. The Health Education Authority cites 26 case studies, ${ }^{2}$ but only one is based in primary care: a health centre in Essex where reorganised work patterns reduced stress. The associated 
research programme, which should lead to better estimates of staff sickness and cost of injury, is likewise hospital based.

The "health at work" campaign and specific initiatives such as alcohol policies lie within the "health promotion" tradition of health in the workplace, which is young compared with the "health protection" tradition.

The health protection tradition has 19 th century roots and is backed by health and safety legislation and a raft of regulations on inspection of workplaces, health and safety committees, control of substances hazardous to health, and reporting of accidents. Employers in primary care are legally obliged to take reasonable measures against foreseeable hazards, which officially include manual handling, violence, infections (including with HIV), needlesticks and clinical waste, radiation, respiratory irritants such as glutaraldehyde, medical devices, and stress. ${ }^{4}$ It is a formidable list and clearly could be added to. Children in clinics, for instance, may endanger themselves, ${ }^{5}$ other patients, or the workforce.

The cleat that unites these two traditions of workplace health is occupational health. Its role is fourfold: to promote adherence to health and safety legislation; assess health on recruitment; surveillance-for example, injuries, hepatitis B status, and sickness absence; and health promotion and education for the workforce. Occupational health thus enables employers to deliver what the law requires or what public health advocates, and is not expensive, at $£ 50$ or less per employee per year. This looks especially cheap when set against the cost of a medically inappropriate recruitment or of unmanaged long term absence due to sickness in a small primary care team. Yet moves to purchase this or similar health benefits for staff may be hamstrung by the funding regulations of family health services.

Better workplace health for primary care will in any event depend on self help by its practitioners, who will need to be convinced of its business value. Uniprofessional approaches continue to have a place (witness the rapid decline in hepatitis $B$ among dentists ${ }^{6}$ ), but schemes such as the sick doctors scheme deal with late effects. Tackling stress, which often stems from relationships in the primary care team and with patients, calls for a team approach. The health commissions should research their local situation and facilitate practices' efforts. They can remain free of the enforcement role, which lies with the health and safety inspectorate.

Commissioners should also look beyond the four contracted professions to the wider penumbra of primary workers such as chiropodists and staff of nursing homes, and beyond those into the general commercial environment. That environment is mainly one of small businesses-shops, garages, light industrial units, and so on-which in our area make up $90 \%$ of employers. ${ }^{7}$ These will have many of the constraints but few of the strengths seen in primary care. Any serious attempt to improve the health of the nation's workplaces must encompass them, but improving health in the small business of primary care is an obvious early step in the learning curve.

RUTH JACKSON

Research student

Wakefield Healthcare,

Wakefield WF1 1LT

GRAHAM C SUTTON Honorary lecturer

Nuffield Institute for Health,

Leeds LS2 9PL

1 Department of Health. The health of the nation, A strategy for health in England. London: HMSO, 1992. ( $\mathrm{Cm} 1986$.

2 Health Education Authority. Working well - a guide to success. London: HEA, 1994.

NHS Management Executive. Towards smoke-free NHS premises. Heywood, Lancashire: Department of Health, 1992. (HSG(92)41.)

4 NHS Executive. Occupational health services for NHS staff. Heywood, Lancashire: Department of Health, 1994. (HSG(94)51.)

5 Doctor fined $£ 750$ over boy who drank acid at surgery. Yorkshire Post 1992 Nov 4:1.

6 Collins M, Heptonstall J. Occupational acquisition of acute hepatitis B infection by health care workers: England and Wales 1985-1993. CDR Rev 1994;4:R153-5.

7 Wakefield Training and Enterprise Council. Corporate plan executive summary. Wakefield: WTEC, 1994.

\title{
Children's dental health and medicines that contain sugar
}

\author{
Doctors must take the lead by prescribing sugar free medicines whenever possible
}

Dental caries is a multifactorial disease, but the primary aetiological agent is sugar. To help children and their parents control dental caries the frequency of sugar consumption must be reduced. Many people equate this with cutting down on sweets, but they are often unaware of the sugars in foods and drinks such as biscuits, cakes, breakfast cereals, baby drinks, cordials, and soya milk. Another commonly used product that contains sugar and is given to children regularly is liquid medicine.

Since 1984 the British National Formulary has warned that "Although liquid preparations are particularly suitable for children, many contain sucrose which encourages dental decay." In view of this harmful effect, doctors have been recommended to prescribe sugar free medicines whenever possible. Previously such advice was difficult to follow because only a few sugar free medicines were available, but the pharmaceutical industry has responded by reformulating old preparations and producing new varieties that do not contain sugar. The British National Formulary and MIMS (the monthly index of medical specialties) specifically indicate medicines that are sugar free; the drug dictionaries on some computerised prescribing systems also indicate preparations that are sugar free. Despite these positive steps, medicines that contain sugar are still the ones most commonly prescribed by doctors and sold by pharmacists. ${ }^{2}$

To promote the use of sugar free medicines a campaign was organised in the north west of England, targeting doctors, pharmacists, health visitors, and mothers with young children. ${ }^{3}$ The pharmacists showed great enthusiasm for this campaign, but when questioned they highlighted two problems. Firstly, doctors usually prescribed medicines containing sugar and rarely offered sugar free alternatives. Secondly, the act of prescribing medicines containing sugar was seen as endorsing their use. The pharmacists reported that they would have liked to give a sugar free medicine when dispensing a prescription but current regulations forbade them. If a doctor prescribes a generic medicine and does not specify SF on the prescription then a drug that contains sugar has to be dispensed even if both the pharmacist and the parent would prefer a sugar free preparation. This impasse could be remedied if doctors could be persuaded to write SF on their prescription.

When doctors in the north west of England were questioned about prescribing sugar free medicines some expressed concern about their palatability: poor palatability might compromise compliance. ${ }^{4}$ This does not seem to be a 